\title{
Oral Submucous Fibrosis: A Clinico-Histopathological Comparative Study in Population of Southern Rajasthan
}

\author{
Saurabh Goel ${ }^{1 \star}$, Junaid Ahmed ${ }^{2}$, Mohit Pal Singh ${ }^{3}$ and Prashant Nahar
}

${ }^{1}$ Senior Lecturer, Department Of Oral Medicine \& Radiology, Pacific Dental College \& Hospital, Udaipur, Rajasthan

${ }^{2}$ Professor \& Head Of The Department, Department of Oral Medicine \& Radiology, Pacific Dental College \& Hospital, Udaipur, Rajasthan

${ }^{3}$ Associate Professor, Department of Oral Medicine \& Radiology, Pacific Dental College \& Hospital, Udaipur, Rajasthan

${ }^{4}$ Associate Professor, Department Of Oral Medicine \& Radiology, Pacific Dental College \& Hospital, Udaipur, Rajasthan

\begin{abstract}
Background: Oral submucous fibrosis (OSMF) is a precancerous condition associated with the use of betel/areca nut in various forms. It is characterized by restricted mouth opening, tongue protrusion and cheek rigidity.

Purpose: To correlate the clinical staging with histopathological grading in OSMF patients.

Materials and Methods: A hospital-based study was conducted on 100 OSMF cases. A detailed history of each patient was recorded along with clinical examination. Punch biopsy was performed for histopathological correlation. Clinical staging of the disease in terms of the ability to open one's mouth was correlated with histopathological grading.

Results: The male to female ratio of OSMF cases was 5:1. All forms of areca nut products were associated with OSMF. Chewing of panmasala was associated with early presentation of OSMF as compared to chewing of other products of areca nut.

Conclusion: In the present study, statistical analysis showed that there is no significant correlation between clinical staging and histopathological grading. The possibility of difference in the severity and extent of fibrosis in different regions of the oral mucosa and involved muscles were considered as contributory factors for this variation.
\end{abstract}

\section{Introduction}

Oral submucous fibrosis (OSMF) is a potentially malignant disorder that primarily affects any part of the oral cavity and sometimes the pharynx. The disease is chronic, insidious and progressive in nature. This generalized condition of the mouth eventually becomes a debilitating disease with mucosal rigidity causing discomfort, burning and limitation of opening of the mouth. People with OSMF carry a high risk for development of oral cancer. OSMF is predominantly found among the people of South Asia and is closely associated with the habit of betel quid chewing. Several case control studies show evidence that areca nut, a constituent of betel quid, greatly contributes towards exaggerating the occurrence of OSMF.

It is generally observed that the onset of OSMF is insidious and takes about 2-20 years to present with symptoms. Submucosal fibrosis of different areas of the oral mucosa leads to difficulty in opening the mouth. Blanching of the oral mucosa is an important clinical feature seen in the early stage of OSMF [1,2] (Figure1). The present study had been undertaken to correlate the clinical staging of mouth opening with histopathological grading in OSMF patients.

\section{Materials and Methods}

A total of 100 cases which were clinically diagnosed as OSMF were selected for this study. A detailed case history and clinical examination was done in visible light using a mouth mirror and a probe in the Department of Oral Medicine. Clinical criteria for the diagnosis of OSMF were difficulty in opening the mouth and associated blanched oral mucosa with palpable fibrous bands. Cases complaining of difficulty in opening the mouth due to other reasons like inflammation etc were excluded from the study. The distance between the inter-incisal edges was measured in $\mathrm{mm}$ for assessing the ability to open the mouth. Punch biopsy was done with the patient's consent.

OSMF cases were clinically categorized into three clinical stages according to their ability to open the mouth. Kiran Kumar et al. [3].
Stage I - Mouth opening $\geq 45 \mathrm{~mm}$

Stage II - Restricted mouth opening 20-44 mm

Stage III - Mouth opening $<20 \mathrm{~mm}$

Patients' chewing habits were categorized as: Betel nut

Betel quid: Use of betel leaf, lime and betel nut along with tobacco.

Panmasala: Various commercial brands in which the main ingredient is areca nut, to which sweetening and flavouring agents are added.
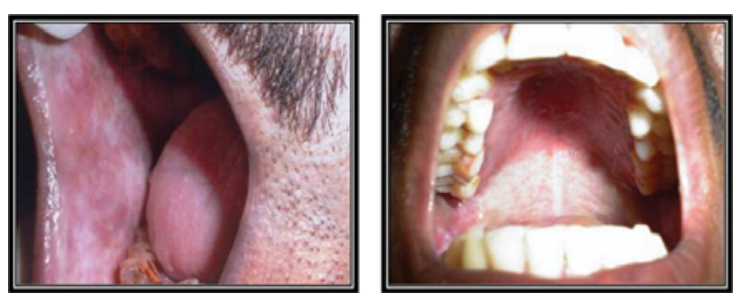

Figure 1: Blanched Oral Mucosa In Osmf Patients.

*Corresponding author: Saurabh Goel, Senior Lecturer, Department of Ora Medicine \& Radiology, Pacific Dental College \& Hospital, Airport Road, Debari, Udaipur, Rajasthan, India, Tel: 9982269698; Fax: 0294-2491508; E-mail: drsaurabh2008@yahoo.com

Received September 30, 2010; Accepted October 27, 2010; Published October 27, 2010

Citation: Goel S, Ahmed J, Singh MP, Nahar P (2010) Oral Submucous Fibrosis: A Clinico-Histopathological Comparative Study in Population of Southern Rajasthan. J Carcinogene Mutagene 1:108. doi:10.4172/2157-2518.1000108

Copyright: ( 2010 Goel S, et al. This is an open-access article distributed unde the terms of the Creative Commons Attribution License, which permits unrestricted use, distribution, and reproduction in any medium, provided the original author and source are credited. 


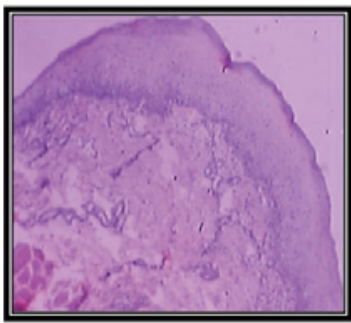

GRADE-I OSMF (10x)

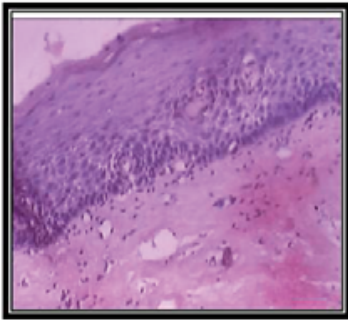

GRADE-II OSMF (10x)

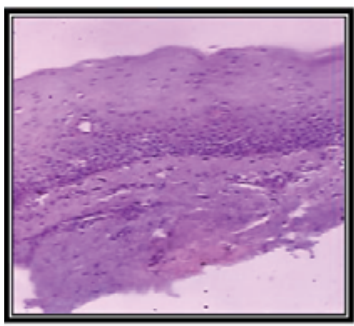

GRADE-III OSMF (10x)

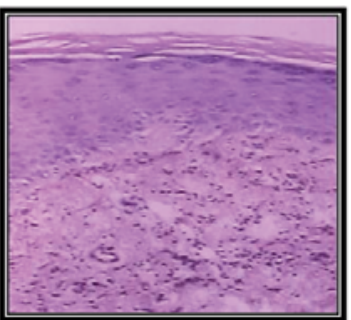

GRADE-I OSMF (40x)

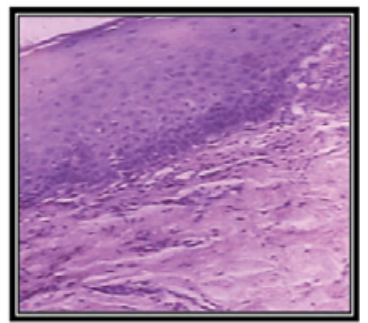

GRADE-II OSMF (40x)

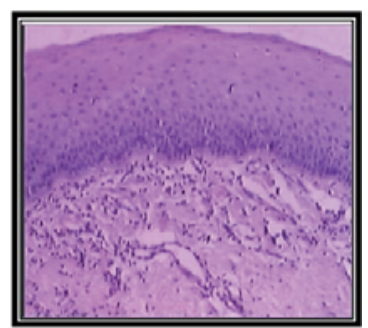

GRADE-III OSMF (40x)
Figure 2: Different Histopathological Grades Of Osmf (10x \& 40x).

The biopsy tissue was processed for paraffin embedding. Sections of 5 micrometer thickness were used for Haematoxylin and Eosin $(\mathrm{H} \quad \& \quad$ E) staining. The sections were studied under a binocular light microscope (Figure 2). The histopathological grading followed in the study Kiran Kumar et al. [3].

Grade I- loose, thin and thick fibres

Grade II- loose or thick fibres with partial hyalinization

Grade III- complete hyalinization

\section{Statistical analysis}

Data analysis and database management were done using SPSS (Statistical Package for Social Science) version 11. Person's Chi-square test was done to determine the association between variables. Student t-test was utilized to find out the mean age difference between genders. A significance level of $\mathrm{p}<0.05$ was used for all tests and comparisons.

\section{Results and Discussion}

The study included a total of 100 subjects of OSMF. Data was collected, results were tabulated and statistical analysis was done.

The results are discussed under the following headings:

1. Correlation of age with clinical staging and histopathological grading. In the present study, the age of the patient was ranging from 20-49 years with a peak incidence from 21 to 29 years of age. Half of the study population was in the age group of 2029 years. Younger age group affected more with OSMF than the older age group. The mean age of occurrence was lower in males than in females and the difference was statistically significant $(\mathrm{P}<0.027)$.

2. Correlation of habits with clinical staging and histopathological grading. In the present study, the exposure to the total burden of various harmful substances in a given period i.e daily consumption was more significant than the total duration of the habit. In addition, onset of OSMF changes occurred earlier with panmasala chewing compared with areca nut/quid chewing. Absence of betel leaf, which has anti-oxidant properties and a consequently higher dry weight proportion of areca nut were responsible for early development of OSMF and this emphasizes the important role of betel/areca nut in etiology of OSMF.

3. Correlation of gender with clinical staging and histopathological grading. Of the 100 cases of OSMF studied, $84(84 \%)$ cases were males and $16(16 \%)$ cases were females. In our study, male to female ratio was $5: 1$.

4. Comparison of clinical staging and histopathological grading. We did not find any significant correlation between clinical staging and histopathological grading. The correlation between clinical staging of mouth opening and histological grading of fibrosis did not show any statistical significance.

OSMF, a potentially premalignant condition of the oral cavity and oropharynx has been a subject of extensive research since the last 50 years. It occurs predominantly in Indians and people of south East Asian Origin, with sporadic cases being reported from other parts of the globe like USA, UK, China and South Africa [4].

Extensive studies have been done by various workers on epidemiology, etiological factors and clinical parameters across the globe, but no breakthrough has been reported. Earlier literature focuses on the studies done by Joshi, Shirat and Khanolkar, ABN Rao and various other workers pertaining to etiology, clinical features, histopathological features and malignant potential of the disease [4].

In the present study, the age of the patient was ranging from 20-49 years with a peak incidence from 21 to 29 years of age (Table 1). Half of the study population was in the age group of 20-29 years. The mean age in our study was 29.3 years consistent with 29.04 years by Katharia and 30 years by Maher [5]. This observation is different from that of Pindborg et al. [3,7] who reported the maximum number of OSMF cases in the age group of 40-49 years in their study. This changing trend of the disease presently indicates that involvement of more number of younger age group and this could be because of increased social encounters and economic liberty they get at this age in a rapidly developing nation like India. Therefore, during this age they indulge in various chewing habits such as betel nut, betel quid and panmasala etc, either to relieve stress or as a fashion. The mean age of occurrence was lower in males than in females and the difference was statistically significant $(\mathrm{P}<0.027)$.

In the present study, patients had one or the other habit of chewing panmasala, betel quid alone or in combination, of which areca nut was one of the major constituents. In our study group, the patients had the habit of chewing either raw areca nut or the commercial areca nut products. Out of 100 patients, $40(40 \%)$ patients chewed panmasala, $30 \%$ chewed betel nut and the remaining $30 \%$ chewed betel quid (Table 2). We also observed that the mean duration of the habit in those who chewed betel quid was eleven years while 
it was ten years for betel nut chewers and nine years for panmasala chewers. The comparison of duration of habit was not statistically significant. This was consistent with the observation made by Shah who stated that the total duration of the chewing habit was not significantly correlated to OSMF [3]. We also found that the patients who used panmasala with a greater frequency/day developed OSMF with a shorter duration of the habit. This means that the exposure to the total burden of various harmful substances in a given period i.e daily consumption was more significant than the total duration of the habit. A similar observation was also reported by Maher who stated that the daily consumption rate appears to be much more significant with respect to risk than the life long duration of the habit [3]. In addition, onset of OSMF changes occurred earlier with panmasala chewing compared with areca nut/quid chewing. Absence of betel leaf, which has anti-oxidant properties and a consequently higher dry weight proportion of areca nut were responsible for early development of OSMF and this emphasizes the important role of betel/areca nut in etiology of OSMF [3].

Of the 100 cases of OSMF studied, 84 (84\%) cases were males and $16(16 \%)$ cases were females (Table 3). A literature survey shows a wide variation in age and sex distribution of OSMF. A male predominance in OSMF cases was shown by Sinor et al. $[4,5]$ in India. In our study we observed that male to female ratio was 5:1. A similar finding was observed by Dave who stated that male to female ratio was 2.3:1 [4].

It has been observed that OSMF can affect any or all parts of the oral mucosa, but buccal mucosa remains the most commonly involved site followed by involvement of soft palate uvula, lips, tongue and floor of the mouth as has been observed in the present study as well as in the previous studies of ABN Rao, Pindborg and Dave [4].

It is reported that the average mouth opening was $47.5 \mathrm{~mm}$ and $44.6 \mathrm{~mm}$ in males and females respectively, based on inter-incisal distance. We grouped our OSMF patients into three clinical stages according to Ranganathan et al. [3]. Out of 100 cases, 12 were found to be in stage I, 68 in stage II and 20 in stage III. Clinically maximum numbers of cases were found in stage II. The reason for this could be attributed to the wide range of mouth opening in clinical stage II i.e $20-44 \mathrm{~mm}$. Similar findings were observed by Tupkari in his study on 101 cases and he reported maximum cases belonging to stage II and III [4].

OSMF is a disease of altered collagen metabolism. The lesion is characterized by increased collagen fibre formation in the initial stages followed by formation of dense collagen fibre bundles and different degrees of hyalinization. This alters the flexibility of the mucosal tissue leading to restriction in the ability to open the mouth [6]. Out of 100 cases, 12 were in histopathological grade I, 54 in grade II and 34 in grade III and $52 \%$ of the males and $62 \%$ female were in grade II.

$45 \%$ of the patients in grade II had a habit of chewing commercially available panmasala. $47 \%$ of the patients in grade III had a habit of chewing betel/areca nut. So betel/areca nut and panmasala as compared to betel quid is more responsible for development of OSMF, this could be probably due to use of more dry weight of areca nut and tobacco. Similar findings were observed by Pindborg and Hamner that the degree of histological changes mostly depends upon amount of betel/areca nut and tobacco used $[7,8]$.

Haider who studied the clinical and functional grading of 228 OSMF patients concluded that the bands are formed initially in the fauces, followed by the buccal and labial areas [3]. This is accompanied by an increase in the severity of the disease as measured by restriction in the ability to open the mouth. In our study, the site of biopsy was in the anterior buccal region, a site accessible to the surgeon to perform punch biopsy. Patients with histopathological grading II could have had more collagenous bands in the posterior region, which could have been fewer in the anterior region. This may be

\begin{tabular}{|c|c|c|c|c|c|c|}
\hline \multirow[t]{2}{*}{ AGE GROUP (YRS) } & \multicolumn{3}{|c|}{ CLINICAL STAGING } & \multicolumn{3}{|c|}{ HISTOPATHOLOGIAL GRADING } \\
\hline & STAGE I (\%) & STAGE II (\%) & STAGE III (\%) & GRADE I (\%) & GRADE II (\%) & GRADE III (\%) \\
\hline $20-24$ & 04(11.76\%) & $26(76.48 \%)$ & $04(11.76 \%)$ & 04(11.76\%) & $18(52.94 \%)$ & $12(35.30 \%)$ \\
\hline 25-29 & $00(00.00 \%)$ & $18(90.00 \%)$ & $02(10.00 \%)$ & $00(00.00 \%)$ & $14(70.00 \%)$ & $06(30.00 \%)$ \\
\hline $30-34$ & $02(25.00 \%)$ & $04(50.00 \%)$ & $02(25.00 \%)$ & $00(00.00 \%)$ & $04(50.00 \%)$ & $04(50.00 \%)$ \\
\hline $35-39$ & $02(14.28 \%)$ & $06(42.86 \%)$ & $06(42.86 \%)$ & $02(14.28 \%)$ & $06(42.86 \%)$ & $06(42.86 \%)$ \\
\hline $40-44$ & $02(14.28 \%)$ & $06(42.86 \%)$ & $06(42.86 \%)$ & 02(14.28\%) & $08(57.15 \%)$ & $04(28.57 \%)$ \\
\hline 45-49 & $02(20.00 \%)$ & $08(80.00 \%)$ & $00(00.00 \%)$ & $04(40.00 \%)$ & $04(40.00 \%)$ & $02(20.00 \%)$ \\
\hline Total & $12(12.00 \%)$ & $68(68.00 \%)$ & $20(20.00 \%)$ & $12(12.00 \%)$ & $54(54.00 \%)$ & $34(34.00 \%)$ \\
\hline
\end{tabular}

Table 1: Age VIS Clinical Staging \& Histopathological Grading.

\begin{tabular}{|c|c|c|c|c|c|c|}
\hline \multirow[t]{2}{*}{ HABITS } & \multicolumn{3}{|c|}{ CLINICAL STAGING } & \multicolumn{3}{|c|}{ HISTOPATHOLOGICAL GRADING } \\
\hline & STAGE I (\%) & STAGE II (\%) & STAGE III (\%) & GRADE I (\%) & GRADE II (\%) & GRADE III (\%) \\
\hline BETEL NUT & $02(06.67 \%)$ & $20(66.66 \%)$ & 08(26.67\%) & 02(06.67\%) & $12(40.00 \%)$ & $16(53.33 \%)$ \\
\hline BETEL QUID & $02(06.67 \%)$ & $22(73.33 \%)$ & $06(20.00 \%)$ & 04(13.33\%) & $18(60.00 \%)$ & $08(26.67 \%)$ \\
\hline PANMASALA & $08(20.00 \%)$ & $26(65.00 \%)$ & $06(15.00 \%)$ & $06(15.00 \%)$ & $24(60.00 \%)$ & $10(25.00 \%)$ \\
\hline
\end{tabular}

Table 2: Habits V/S Clinical Staging \& Histopathological Grading

\begin{tabular}{|c|c|c|c|c|c|c|}
\hline \multirow[t]{2}{*}{ GENDER } & \multicolumn{3}{|c|}{ CLINICAL STAGING } & \multicolumn{3}{|c|}{ HISTOPATHOLOGICAL GRADING } \\
\hline & STAGE I (\%) & STAGE II (\%) & STAGE III (\%) & GRADE I (\%) & GRADE II (\%) & GRADE III (\%) \\
\hline MALE & $12(14.29 \%)$ & $60(71.42 \%)$ & $12(14.29 \%)$ & $12(14.28 \%)$ & $44(52.38 \%)$ & $28(33.33 \%)$ \\
\hline FEMALE & $00(00.00 \%)$ & $08(50.00 \%)$ & $08(50.00 \%)$ & $00(00.00 \%)$ & $10(62.50 \%)$ & $06(37.50 \%)$ \\
\hline TOTAL & $12(12.00 \%)$ & $68(68.00 \%)$ & $20(20.00 \%)$ & $12(12.00 \%)$ & $54(54.00 \%)$ & $34(34.00 \%)$ \\
\hline
\end{tabular}

Table 3: Gender V/S Clinical Staging \& Histopathological Grading.

\begin{tabular}{|l|l|l|l|}
\hline & GRADE I (\%) & GRADE II (\%) & GRADE III (\%) \\
\hline STAGE I (\%) & $04(33.33 \%)$ & $08(66.67 \%)$ & $00(00.00 \%)$ \\
\hline STAGE II (\%) & $06(08.82 \%)$ & $36(52.94 \%)$ & $26(38.23 \%)$ \\
\hline STAGE III (\%) & $02(10.00 \%)$ & $10(50.00 \%)$ & $08(40.00 \%)$ \\
\hline TOTAL (\%) & $\mathbf{1 2 ( 1 2 . 0 0 \% )}$ & $\mathbf{5 4 ( 5 4 . 0 0 \% )}$ & $\mathbf{3 4 ( 3 4 . 0 0 \% )}$ \\
\hline
\end{tabular}

Table 4: Clinical Staging V/S Histopathological Grading. 
the reason for the shift of some of the patients in clinical stage II to histopathological grade I and of some patients in clinical stage III to histopathological grades I and II.

In our study, we did not find any significant correlation between clinical staging and histopathological grading (Table 4). Out of 100 patients, 12 cases were in clinical stage I while 4 were in histopathological grade I. There were 68 cases in clinical stage II while 36 were in histopathological grade II. 20 patients were in clinical stage III, out of which 8 cases had histopathological grading III. Although the maximum numbers were seen in clinical stage II and histopathological grade II. The number of cases seen in clinical stage I $(12 \%)$ and clinical stage III $(20 \%)$ showed a marked discrepancy in their histopathological grading. In clinical stage I among the 12 cases, $66.67 \%$ were in histopathological grade II and in clinical stage III, among the 20 cases, $50 \%$ were in histopathological grade II. Similar findings were observed by Rooban et al. [9] and they concluded that the correlation between clinical staging of mouth opening and histological grading of fibrosis did not show any statistical significance [9]. The possibility of a difference in the severity and extent of fibrosis in different regions of the oral mucosa and involved muscles were considered as contributory factors for this variation.

\section{Conclusion}

A better understanding of the correlation between clinical staging and histopathological grading can provide to be a good marker for the diagnosis, prognosis and severity of this multifactorial crippling disease. Further research must be aimed into genetic, environmental, immunologic and nutritional interactions in the pathogenesis of OSMF. The study points towards the need for planning oral health education programme for youngsters and teenagers to refrain them from various betel nut chewing habits particularly panmasala chewing, which is the more prevalent habit in this age group.

\section{Acknowledgement}

We thank the staff of department of oral \& maxillofacial pathology for their help in investigative procedure.

\section{References}

1. Daftary DK, Murti PR, Bhonsle RB, Gupta PC, Mehta FS, et al. (1993) Ora precancerous lesions and conditions of tropical interest. In Oral diseases in the tropics. eds. Prabhu, S.R., Wilson, D.R., Daftary, D.K. and Johnson, N.W Delhi: Oxford University Press 402-428.

2. Zain RB, Ikeda N, Gupta PC, Warnakulasuriya S, van Wyk CW, (1999) Ora mucosal lesions associated with betel quid, areca nut and tobacco chewing habits consensus from a workshop held in Kuala Lumpur, Malaysia. J Oral Pathol Med 28: 1-4.

3. Kiran Kumar K, Saraswathi TR, Ranganathan K, Uma Devi M, Elizabeth J (2007) Oral submucous fibrosis: A Clinico-histopathologic study in Chennai Indian J of Dent Res 18: 53-59.

4. Sinor PN, Gupta PC, Murti PR, Bhonsle RB, Daftary DK, et al. (1990) A casecontrol study of oral submucous fibrosis with special reference to the etiologic role of areca nut. J Oral Pathol Med 19: 94-98.

5. Lavina T, Bagewadi A, Keluskar V (2007) Haemoglobin levels in patients with Oral Submucous fibrosis. JIAOMR 19: 329-333.

6. Hazarey VK, Erlewad DM, Mundhe KA, Ughade SN (2007) Oral submucous fibrosis: study of 1000 cases from central India. J Oral Pathol Med 36: 12-17.

7. Pindborg JJ, Mehta RS, Gupta PC, Daftary DK (1970) Epithelial atypia in 51 Indian villagers with OSMF. Br J Cancer 24: 253-257.

8. Hamner JE 3rd, Mehta FS, Pindborg JJ, Daftary DK (1971) Altered staining reaction of connective tissue in 53 submucous fibrosis patients. J Dent Res 50: 387-392.

9. Rooban T, Saraswathi TR, Al Zainab FH, Devi U, Eligabeth J, et al. (2005) A light microscopic study of fibrosis involving muscle in oral submucous fibrosis. Indian J Dent Res 16: 1321-1324. 